Article

\title{
Practical Application of an Indigenous Research Framework and Two Qualitative Indigenous Research Methods: Sharing Circles and Anishnaabe Symbol-Based Reflection
}

Lynn F. Lavallée

Ryerson University

Toronto, Ontario, Canada

(C) 2009 Lavallée. This is an Open Access article distributed under the terms of the Creative Commons Attribution License (http://creativecommons.org/licenses/by/2.0), which permits unrestricted use, distribution, and reproduction in any medium, provided the original work is properly cited.

\begin{abstract}
Increasingly research involving Indigenous people is being undertaken by Indigenous researchers, who bring forward worldviews that shape the approach of the research, the theoretical and conceptual frameworks, and the epistemology, methodology, and ethics. Many times such research bridges Western practices and Indigenous knowledges; however, bringing together these two worldviews can also present challenges. In this paper the author explores the challenges and lessons learned in the practical application of an Indigenous research framework and qualitative inquiry. Two qualitative Indigenous research methods, sharing circles and Anishnaabe symbol-based reflection, will be discussed.
\end{abstract}

Keywords: Indigenous, epistemology, Indigenous research framework, Aboriginal, Anishnaabe symbol-based reflection, sharing circles, arts-based research

Author's note: I would like to acknowledge all the participants in this research, including Elder Vern Harper for his guidance throughout the project; Lee Maracle for her assistance in editing this paper; the Native Canadian Centre of Toronto, where the research took place; and the Wellesley Institute for funding the project. 


\section{Introduction}

The epistemological approach of any research fundamentally shapes a project, beginning with what is deemed worthy of researching, what questions are asked, how they are asked, and how the "data" are analyzed (Smith, 2002). The vision for my doctoral research was based on an Indigenous ${ }^{1}$ epistemology and Indigenous ways of understanding the world. In this project what was deemed "worthy" as research and what questions were asked were rooted in the Indigenous teaching of the medicine wheel, which will be described later. Applying an Indigenous framework was natural for me as I am Algonquin, Cree, and French Métis. What was challenging was to find a way of bringing together Indigenous ways of knowing and Western ways of conducting research, specifically qualitative inquiry. The bridging of these two ways of knowing is the focus of this paper.

The research topic focused on the physical, mental, emotional, and spiritual impacts of a physical activity program: a martial arts (tae kwon do) program offered at the Native Canadian Centre of Toronto. Although the research topic is discussed to provide an understanding of the methodology, the focus of the paper is on the methodological process itself. For further discussion of the findings, refer to Lavallée (2007a, 2007b, 2008). The current paper centers on the challenges associated with an attempt to balance an Indigenous research framework with Western principles, particularly qualitative inquiry.

Two qualitative Indigenous research methods, sharing circles and Anishnaabe symbol-based reflection, will be discussed. Sharing circles are similar to focus groups, whereas Anishnaabe symbol-based reflection can be classified as an arts-based method. The latter was named by the people who participated in the piloting of this qualitative research method. The term Anishnaabe identifies the people from which the method was born, the Anishnaabe. Anishnaabe is an Ojibway word meaning "human" (First Ojibway Network, 2006) and is a term used to describe people who identify as Ojibway, Algonquin, Oji-Cree, and Odawa (Eigenbrod, Kakegamic, \& Fiddler, 2003).

\section{Background}

Prior to discussing the methods employed in this research and some of the challenges faced, it is important to explore Indigenous epistemologies and knowledges. A caveat to the discussion is the recognition that knowledge systems of Indigenous peoples vary throughout the world and even within countries; thus, the use of the plural, knowledges and epistemologies. In this paper I have incorporated the knowledge, values, and beliefs of the Ojibway, Algonquin, and Cree Nations in Canada. This paper does not purport to be a pan-Indigenous approach to research. It is a practical application of how one researcher applied Ojibway, Algonquin, and Cree knowledge, values, and beliefs to research.

Indigenous knowledge encompasses three processes: empirical observation, traditional teachings, and revelation (Brant-Castellano, 2000). Empirical observation in this context is not based on quantitative inquiry in controlled settings. Rather, Indigenous empirical knowledge is a representation of "converging perspectives from different vantage points over time" in real-life situations and settings (p. 24). An example would be Indigenous understandings of the medicinal properties of plants.

Traditional teachings encompass knowledge that has been passed down through generations. Knowledge acquired through revelation, such as dreams, visions, and intuition, is sometimes regarded as spiritual knowledge, which is understood as coming from the spirit world and ancestors. Such knowledge is sometimes called "blood memory" (G. Atone, personal communication, February 25, 2002; V. Harper, personal communication, April 12, 2002) because it is believed that thoughts, beliefs, and actions are conveyed from one's ancestors through the blood. Spiritual knowledge cannot be observed by physical means; therefore, as it cannot be measured or quantified, Indigenous spiritual ways of knowing are often dismissed by Western researchers. Of these three sources of knowledge, one is not seen as more important 
or more valid than the others in Indigenous society. All are considered equally valid and interconnected.

The relational nature of Indigenous epistemology acknowledges the interconnectedness of the physical, mental, emotional, and spiritual aspects of individuals with all living things and with the earth, the star world, and the universe. Indigenous epistemology is fluid, nonlinear, and relational (Kovach, 2005). Many Indigenous ways of knowing accept both the physical and the nonphysical realms as reality. In accepting the nonphysical, one must accept that reality cannot always be quantified.

An assumption of positivist research is that the researcher and the research can be objective and neutral (Lincoln \& Guba, 2000). Qualitative researchers have advanced the notion that no research is free from bias; from the inception of the topic to the interpretation of the results, the researchers' point of view affects the research (Berg, 1995; Kilbourn, 2006). An Indigenous epistemology is similar to this qualitative notion but for different reasons. Indigenous research is not objective, nor does it see itself as unbiased. Following from the belief in interconnectedness as outlined above, research cannot possibly be completely objective. Individuals conducting the research are necessarily connected to the individuals being researched, and all concerned are connected to all other living things. Emotions are connected to all mental processes. Every time we think, use reason, and figure, emotion is tied to that process; therefore, it is impossible to be free of emotion and subjectivity in research.

\section{What is an Indigenous research framework?}

The theoretical basis for my research is grounded in Indigenous knowledge. This grounding manifests itself in my everyday practice through a community-based approach. My research incorporates the values and beliefs of Indigenous communities in its design, methods, and analysis. In addition, data dissemination is handled in a way that is appropriate for the community. In the following sections I outline how this Indigenous research framework materialized.

\section{Incorporating Indigenous values and beliefs}

Following an Indigenous research framework involves rewriting and rerighting the Indigenous position in history and society (Smith, 1999). I interpret rewriting and rerighting as a process of decolonizing the academy by incorporating Indigenous knowledge into the research rather than relying on Western theories. The core values, beliefs, and healing practices of the Indigenous community are incorporated throughout the research process. Specifically, I employed an Indigenous teaching, the teachings of the medicine wheel, as the theoretical basis for my research.

Many Indigenous nations in Canada carry cultural teachings of the medicine wheel; however, these teachings differ between nations. In this paper I describe the medicine wheel teachings that I have received through the Algonquin, Ojibway, and Cree Nations. These teachings are vast and can take an entire lifetime to understand. The following explanation outlines a small fraction of these teachings.

\section{The medicine wheel}

The medicine wheel is both a symbol and a tool to understand phenomena. It is a circle divided into four quadrants, or segments, which are separate but interconnected. This state of separateness but interconnectedness is sometimes depicted visually with feathers placed between each quadrant and the four quadrants joining in the centre. The colors of the quadrants vary between nations. For instance, the Cree medicine wheel consists of blue, yellow, red, and white, whereas the Ojibway and Algonquin teachings substitute the blue with black. 
The circle represents infinite life, whereas the four quadrants can represent teachings such as the four races: black, white, yellow, and red. The teaching here is that all races are equal, all are related, and all are interconnected. The story of one cannot be understood outside of the story of the whole. Another teaching of the medicine wheel concerns health and well-being. Health is the balance between the physical, emotional, mental, and spiritual: the four quadrants of the medicine wheel. Health also involves balance with others (family, community), with the environment, and with Mother Earth. Balance is sometimes depicted through interconnecting circles.

The medicine wheel teaching around health and well-being, as described above, formed the theoretical basis for my research. Rather than exploring a Western notion of health, the rationale for my research came from Indigenous knowledge. In my doctoral research I explored the impact of physical activity on health in the holistic sense: physical, mental, emotional and spiritual well-being. The physical activity I examined was a martial arts program offered at the Native Canadian Centre of Toronto. Much of the Western literature exploring this topic focuses on psychosocial development as an impact or aspect of physical activity, sport, or recreation. Much of this research emerges from a positivist paradigm and attempts to confirm or disprove the impact of physical activity, sport, or recreation on specific psychosocial variables such as self-esteem. Many researchers have recognized that a new approach is needed (Canadian Parks and Recreation Association, 1994; Coakley, 2002; Halas, 2001; Hartmann, 2003). The Indigenous research framework and the use of the medicine wheel are capable of providing this alternative approach.

\section{Developing an ethical relationship with the community}

Within an Indigenous research framework the way in which the researcher interacts with participants is of paramount importance, not unlike in community-based research. As Minkler and Wallerstein (2003) have stated, community-based research "equally involves all partners in the research process and recognizes the unique strengths that each brings. Community-based research begins with a research topic of importance to the community with the aim of combining knowledge and action for social change” (p. 4). This definition of community-based research is ideal, but in practice there are varying degrees of community participation, which can be mapped against a continuum of involvement. The range spans from token involvement to full involvement, in which community members shape the research question, design, methods, analysis, interpretation, and dissemination. Research involving Indigenous peoples should sit on the latter end of this continuum. In addition, research with the Indigenous community is a commitment that extends well beyond the final report, dissertation, peer-reviewed article submission, or conference presentation. It is a lifelong relationship and commitment. If contacted by the community, even many years after the completion of a research project, the research team must be prepared to assist the community with their requests.

To understand how Indigenous research differs from community-based research, one can explore the guidelines that have emerged on how to conduct research with Indigenous Peoples. In Canada, for example, the Steering Committee of the First Nations Regional Longitudinal Health Survey stated that principles of ownership of research and data, control of the research, access to the data, and possession (OCAP) are paramount. These principles were established to provide specific direction on how the community should be involved in the research process and how research with Indigenous peoples should be conducted (Schnarch, 2004). More recently, the Canadian Institutes of Health Research (CIHR) published 15 guidelines for research involving Aboriginal people. The first refers to understanding and respecting Aboriginal worldviews, specifically the responsibilities around access to traditional or sacred knowledge (CIHR, 2007). The University of South Australia (2008) requires research involving Aboriginal people or Torres Strait Islanders to undergo ethical review by the David Unaipon College of Indigenous Education and Research. These guidelines refer to six core components: reciprocity, respect, equality, responsibility, survival and protection, and spirit and integrity (National Health and Medical 
Research Council, 2003). In addition, Indigenous communities themselves are developing research ethics guidelines. For instance, in Canada the Mi’kmaq Nation (eastern Canada) established principles and guidelines under Mi'kmaw Ethics Watch, an organization established to protect Mi'kmaq peoples and their knowledge. Mi'kmaw Ethics Watch states, "Any research, study, or inquiry into the collective Mi'kmaw knowledge, culture, arts, or spirituality which involves partnerships in research shall be reviewed by the Mi’kmaw Ethics Watch” (Mi’kmaw College Institute, n.d.).

Although the above-noted guidelines provide direction, the specific ways in which these guidelines and principles are addressed are left to the researchers and community to decipher. To compound matters, the ways in which Indigenous knowledge is applied in research vary because of differences between communities in cultural traditions and teachings. Therefore, it is crucial that literature be further developed to gain a better understanding of the ways of conducting research among Indigenous communities. At present, there is a growing body of literature related to the ethical challenges and inherent tensions between an Indigenous approach and a traditional academic one. For instance, Piquemal (2001) and Meadows, Lagendyk, Thurston, and Eisener (2003) have discussed the challenges posed by the standard ethics consent forms that are required by universities and the need for an oral consent process. Loppie (2007) has discussed how she incorporated Indigenous principles and Western science into her doctoral research process, particularly by acknowledging the wisdom of elder women.

As more research is undertaken, the body of practical knowledge about conducting research among Indigenous communities will increase. Simultaneously, Indigenous ways of knowing will be advanced within the academy. It is important that the research studies that advance these efforts be disseminated widely, from Web-based community reports to academic journals and that the results reach nonIndigenous and mainstream forums. This paper is one such attempt to bring Indigenous ways of knowing into the academy.

\section{Program and participant profiles}

Participants in this project were members of the Native Canadian Centre of Toronto, an Aboriginal cultural and recreation centre. The martial arts program had been part of the Native Canadian Centre since 1999. The program was equally a social, cultural, and spiritual program. The instructor, of Cree ancestry, brought his Aboriginal teachings into the classroom. For example, he ensured that an elder was affiliated with the program and attended significant events. During classes he referred to specific Aboriginal teachings. The instructor was a 7th degree black belt in tae kwon do, a 6th degree black belt in hapkido/ tae keuk do, and the founder of Oki Chi Taw, an Indigenous martial art and combat system of Canada. Oki Chi Taw focuses on weaponry of the Plains Cree, such as the tomahawk, gunstock war club, short lance, and long knife. Oki Chi Taw is recognized by the World Martial Arts Union as the official Indigenous martial art of Canada (Native Canadian Centre, 2006). Although tae kwon do was the focus of the program, the instructor would also bring in concepts from other martial arts (hapkido, tae keuk do, and Oki Chi Taw). Note that the terms martial arts and tae kwon do are used interchangeably throughout this paper, particularly by the participants. Both terms refer to the same program.

Research in an urban Aboriginal community is different from that conducted in on-reserve ${ }^{2}$ communities. Reserve communities tend to be more homogenous and typically consist of a dominant nation (e.g., Ojibway). The present research did not involve a single nation; rather, as it took place in a Canadian urban center, it included many nations. Consequently, the research had to respect a wide range of people with both similar and differing customs. Most of the Aboriginal participants of this research were of Ojibway, Cree, and Métis heritage. Therefore, the primary considerations for the research framework reflected the customs, beliefs, and practices of these groups. 
The Native Canadian Centre of Toronto and the martial arts program have an inclusive policy, whereby non-Aboriginal people are welcome. Prior to participant recruitment, I consulted with the elder and with the instructor of the program as to whether non-Aboriginal members should be invited to participate because the focus of the research was on the experiences of Aboriginal people. We agreed that the principles of the Native Canadian Centre of Toronto should be followed and that non-Aboriginal people should be included if they wished to participate. It was felt that excluding non-Aboriginal people would be inconsistent with the philosophy of the program, the Native Canadian Centre, or the medicine wheel teachings. The non-Aboriginal people involved in the martial arts program and in the research were nevertheless familiar with Aboriginal customs because of their involvement in the Native Canadian Centre.

Seventeen people, 10 male and 7 female, volunteered to be part of the project. They ranged in age from 26 to 49 years, with an average age of 34. Eleven of the participants identified as Aboriginal (Ojibway, Cree, and Métis), one identified as Indigenous from South America, one as from Ecuador, one as from Barbados, one as Greek, and two as White.

\section{Location of the researcher and the challenge with ethical review}

Locating oneself as a researcher is important, particularly within an Indigenous research framework (Absolon \& Willett, 2005; Baskin, 2005; Restoule, 2004). A positivist epistemological framework boasts that the researcher is objective and neutral. Within postpositivist and constructivist/interpretivist paradigms researchers sometimes locate themselves to identify potential biases. The rationale for locating oneself within an Indigenous research framework is similar. Within many Indigenous communities we begin by identifying ourselves: who we are, where we are from, who our ancestors are. This identification allows people to know who we are, which, in turn, helps to establish trust (Absolon \& Willett, 2005) as people can then identify the worldview from which they speak. The practice extends into research. Indigenous scholars and researchers identify themselves within the research (as I did briefly at the beginning of this paper).

When locating ourselves within the research, it is also important to recognize that personal growth is an important end product. As Bastien (2005) has noted, researchers personally benefit from research and are inevitably affected by the research undertaken. For me, the research project became a tremendous learning journey that included growing spiritually, exploring my identity as an Aboriginal person, and receiving an indescribable amount of knowledge from the community.

My initial interest in this research topic was sparked by a culmination of past experiences, including sport and recreation experience, membership in the Native Canadian Centre of Toronto, and participation in the martial arts program. Minkler and Wallerstein (2003) have stated that community-based research is strengthened when the researcher comes from the community. However, I was mindful of the fact that my interest in the topic did not guarantee that the community would share my interest. For this reason, I began by meeting with the instructor of the program, the elder affiliated with the program, and the Board of Directors of the Native Canadian Centre to discuss the proposed project. All were supportive and interested in the research. I continued to work closely with the instructor and the elder during development of the research design. I confirmed my role as steward of the data and the fact that the community owned the project. The community was very open and trusting, so much so that they would often turn my questions back and ask me what I thought, effectively making me a participant and themselves stewards. This switching and overlap of roles is part of the fluidity of the process.

The greatest challenge I had with this research came at the ethical review stage at the university. At the outset, the Ethical Review Board (ERB) took a mainstream approach, questioning my relationship with the community and raising the possibility of a conflict of interest. I was able to satisfy their concerns by 
referencing community-based literature, specifically Minkler and Wallerstein (2003). A second challenge arose around project funding because I elected to have the funding flow through the Native Canadian Centre as opposed to the university. I pointed out that the funding was part of a community-based research initiative and that the funder supported having funds flow through the community agency. I was able to get support from members of my research committee and the research funder to address these concerns, and, after much effort, both the project and the funding mechanism were approved.

\section{Involvement of our elders}

Elders are an important part of Aboriginal culture because of the traditional knowledge that they impart. They carry the traditional teachings, the ceremonies, and the stories of all our relations. For research to be based on Aboriginal knowledge, elders need to be included. Reserve communities typically have a band council and engage specified elders to act as advisers. Researchers typically address the band council and/or elders before doing research with the community. Although an urban Aboriginal community does not have a band council, there are nevertheless recognized elders. In Toronto, an Elders and Traditional Peoples Council, called the Taam Kaadinakiijik Council, provides guidance for the community. Seeking guidance of elders would require researchers to become familiar with the urban Aboriginal community prior to starting any research.

As noted earlier, the elder affiliated with the martial arts program provided guidance throughout the project. When I had questions related to the research, such as who should be included and what cultural protocols needed to be followed, the elder was my first contact. When the project was complete and I neared the defense stage of my doctoral program, I reflected on the elder's involvement and felt it was important that his knowledge and contribution be formally recognized. At the University of Toronto doctoral defenses are closed to anyone other than the research committee. Observers can attend, but they require prior approval. As the elder had not simply been an observer throughout the research process, I did not want him only to observe at my defense. Instead, I wished him to be a voting member of the academic committee who contributed to the decision of whether I passed or failed.

I contacted First Nations House, student services for Aboriginal students at the University of Toronto, to see if they could assist. The director informed me that he had previously had discussions with the School of Graduate Studies, and the school was keen on developing a policy related to the matter. I was able to work directly with the School of Graduate Studies to implement the process of having my elder acknowledged as an associate faculty member so that he could become a voting member on my committee. There was no opposition from the university or the research committee. The most challenging aspect of the process was attempting to develop the elder's curriculum vitae, required for recognition as an associate faculty member of the university. We met on several occasions to develop the curriculum vitae that would acknowledge the many accomplishments the elder had achieved in his 70 years.

\section{Medicines}

A cultural consideration for this research project concerned the importance of "medicines" to the people involved in the project. Once again, the people involved in this research were primarily from the Ojibway, Cree, and Métis Nations. Through my Algonquin, Cree, and Ojibway teachings, I understand that plants and animals provide medicine for us. Tobacco is considered one of the most sacred plants in some Indigenous communities on Turtle Island (North America). Tobacco is placed in a cloth bundle and given as a gift to an elder when seeking advice. These bundles are also given to a person when requesting knowledge or help. This is done to ensure that things are done in a respectful or good way. Accepting a bundle carries a responsibility to do what is asked of you. If the recipient feels unable to carry out what is expected, he or she does not accept the tobacco. 
Many Indigenous researchers have included the use of the tobacco as a gift to participants to demonstrate respect for the knowledge that the participant will be providing and to ensure that the research is done in a good way (Baskin, 2005; Restoule, 2004). Some researchers have suggested that the practice of presenting tobacco bundles could replace the written informed consent process entrenched in our ethical review processes at the universities (Davidson, Brown, \& Moffit, 2006; Ellis \& Early, 2006). Although I agree with this challenge to ethical review boards on the issue, I chose not to issue such a challenge because of the other difficulties I had with the ERB. I chose to direct my energies toward ensuring that the funding would flow through the community agency and that the elder would be accepted as a voting member of my committee.

Any discussion of incorporating cultural protocols into Aboriginal research requires a preliminary discussion of colonization and cultural genocide and of the effect that these have had on Aboriginal people. Colonization has been effective in assimilating many Aboriginal people (Wesley-Esquimaux \& Smolewski, 2004). It has also caused many Aboriginal people to be ashamed of their culture. As a result, many Aboriginal people in Canada do not understand the significance of certain cultural protocols and might not wish to take part in cultural aspects of a research study. Individuals should be allowed to decide for themselves whether they want to participate in research and the degree to which they wish to participate in Indigenous aspects of the research. Some Aboriginal research participants might not have the teaching about tobacco being a sacred gift, or this might not be a teaching from their nation. However, even after learning about the significance of tobacco, Aboriginal research participants might not wish to accept tobacco but might still want to be part of the research. Others might accept the tobacco out of respect for the cultural protocols being followed in the research but might not adhere to this belief. Either decision by the participant is acceptable. Researchers should be prepared to teach or to have an appropriate person teach about the significance of certain research protocols so that participants are able to make an informed decision.

For Algonquin, Ojibway, and Cree Nations, sage and sweetgrass are also considered sacred plants. The sage or sweetgrass is burned and the smoke used to cleanse a room, people, or objects. Sage or sweetgrass is often burned before a ceremony or event. This practice is called smudging or purification ceremony (G. Antone, personal communication, November 10, 2002). As explained below in the Sharing Circles section, tobacco bundles and smudging were cultural protocols used in this research.

\section{Indigenous research methods}

Restoule (2004) described Indigenous methods as incorporating experiential learning where the participant is fully engaged. The method, the actual technique of data collection, is respectful of and includes Indigenous protocols, values, and beliefs that are important to the specific community. The two methods used to gather the stories of participants in this study were sharing circles and Anishnaabe symbol-based reflection. These two methods are classified as qualitative because they do not involve the collection of numeric data.

\section{Sharing Circles}

\section{Description}

The gathering of stories explores lived experience and can be defined as existential phenomenological inquiry (van Manen, 2002) or narrative research, which consists of a range of methods, including ethnobiography, analyzing biographies, and narrative interviewing (Casey, 1996). In keeping with an Indigenous research framework and resisting of Western labels, I describe this method of inquiry as gathering stories through sharing circles. Sharing circles are used to capture people's experiences. They are comparable to focus groups in qualitative research where researchers gather information on a 
particular topic through group discussion (Berg, 1995). How they differ from focus groups is the sacred meaning they have in many Indigenous cultures and in the growth and transformation bases for the participants.

Sharing circles use a healing method in which all participants (including the facilitator) are viewed as equal and information, spirituality, and emotionality are shared, a method that is familiar and comforting for some Aboriginal participants in Canada who have this knowledge of this practice (Restoule, 2004). Healing circles and learning or sharing circles are used as part of ceremony and as a way of healing (Stevenson, 1999), and in these contemporary times are increasingly used by Indigenous researchers (Baskin, 2005; Restoule, 2004). In a research setting, although both the focus group and the sharing circle are concerned with gaining knowledge through discussion, the principles behind a sharing circle are quite different. Circles are acts of sharing all aspects of the individual—heart, mind, body, and spirit—and permission is given to the facilitator to report on the discussions (Nabigon, Hagey, Webster, \& MacKay, 1999).

Nabigon et al. (1999) acknowledged the following as being important considerations for the circle. There is recognition that the spirits of our ancestors and the Creator are present in the circle and guide the process. Energy is created in the circle by the spirit of the people involved. The circle is nonjudgmental, helpful, and supportive. Respect is important, and this includes listening to others. Sometimes people speak as they are seated in the circle, either going in a clockwise or counter clockwise direction and hold an object such as a talking stick or eagle feather. Circles begin with a smudging ceremony to rid the circle and people of negativity. Items may be placed in the centre of the circle, depending on the purpose.

\section{Conducting the sharing circles}

Nine sharing circles with 16 people were carried out. The circles were scheduled at a convenient time for the participants, typically before or after a class. The smallest circle consisted of two people, and the largest had six. All circles included light snacks and beverages.

I had prepared tobacco bundles prior to the sharing circles. At the beginning of the circle I explained what the expectations were for the circle and asked if people would accept tobacco for their participation. I explained the significance of accepting a tobacco bundle, specifically that I wanted to demonstrate my respect for honoring me with their knowledge and wanted things to be done in a good way. I emphasized that although they might accept the tobacco, if during the sharing circle they did not feel like answering a question or sharing something, they did not have to. In addition, if someone wanted to meet with me individually after the circle to share something in confidence, this could be arranged. All 16 participants accepted the tobacco, including the non-Aboriginal participants. One participant asked to meet with me after the circle to elaborate on something she brought up in the circle.

After giving the tobacco bundles, I prepared the smudge. Although all participants were knowledgeable of smudging, I explained what I was doing and asked if anyone did not wish to smudge. Again, none of the participants declined. After the smudge I handed out the Study Information Sheets and Consent Forms and read the instructions. I asked if there were any questions and confirmed that everyone was comfortable with the circle being audiotaped so that I would not have to take notes. All circles were audiotaped, and there were no concerns about the project. I collected the signed consent forms, and the circle began with an open-ended question about if and how the martial arts program affected their lives.

One of the Ojibway participants expressed her gratitude that I did things in a traditional, culturally appropriate way (offering tobacco, smudging, and the sharing circle). She recognized through her undergraduate studies at a university in Ontario that bringing Aboriginal cultural ways into the university setting is sometimes a challenge. 


\section{Anishnaabe symbol-based reflection}

\section{Description}

Anishnaabe symbol-based reflection is an arts-based research approach. Arts-based research is defined as a method of inquiry that uses the elements of the creative arts experience, including the making of art by the participants and/or researcher, as ways of understanding the significance of what we do within our practice and teaching (McNiff, 1998). It is classified as participatory action research (PAR). PAR is a socially conscious research method that directly involves the participants of the research in a practical and real way and aims to empower people and contribute to immediate problematic situations while simultaneously furthering the goals of social science (Park, 1993).

Anishnaabe symbol-based reflection was influenced by a PAR method called photovoice, a research method whereby people identify, represent, and enhance their community through photography. In this process the researcher provides cameras to individuals, enabling them to act as recorders and potential catalysts for social action and change in their own communities. Participants take pictures that help tell their story regarding a particular concern. The individual's story typically accompanies the pictures to promote an effective, participatory means of sharing expertise. The three main goals of photovoice are (a) to enable people to record and reflect their community's strengths and concerns, (b) to promote critical dialogue and knowledge about personal and community issues through large and small group discussions of photographs, and (c) to reach policymakers (Wang, Yuan, \& Feng, 1996). ${ }^{3}$ Anishnaabe symbol-based reflection is an adaptation of photovoice. Instead of using cameras and pictures, participants use other kinds of symbols (e.g., paintings, drawings, sculptures, crafts, songs, teachings, and stories).

Some Aboriginal people believe that when an artist makes something, such as a painting, jewelry, a medicine wheel, or a dream catcher, his or her energy is placed into that object and each piece will have a different energy. Furthermore, the making of symbols and art is a spiritual process unique for each person (K. Wheatley, personal communication, October 4, 2004). Symbols are considered sacred because of this spiritual significance. They describe the meaning that is beyond words. Cajete (2000) stated that "much of the essence of Native science is beyond literal description [and] incorrect or misapplied words often destroy the real and holistic experience" (p. 2). Just as a picture tells a thousand words, symbols are an alternative to words, which might not capture the essence of personal meaning.

\section{Implementing Anishnaabe symbol-based reflection}

At the end of the sharing circle, I introduced the second method, Anishnaabe symbol-based reflection. Doing this after the sharing circles allowed for examples to be used based on what was shared in the circles. I asked participants to think about a symbol or symbols that represented what and how they felt about the physical activity program and how it has influenced their lives, the lives of their families, and/or their community. I worked through some examples so that the participants could gain a deeper understanding of this method. For instance, I selected an example of what someone described in the circle, the martial arts program exposing participants to other cultural activities, such as drumming and full-moon ceremonies. I depicted a picture of a sunrise to describe that awakening of one's cultural experiences as a result of participating in the program at the Native Canadian Centre.

Ten of the 16 people who participated in the sharing circles also participated in the Anishnaabe symbolbased reflection. One member of the program who did not participate in the sharing circles took part in this second method. Therefore, 11 people participated in the Anishnaabe symbol-based reflection.

Participants were told they could make or purchase their symbol. There were no restrictions to what they selected as their symbol; however, they were given up to $\$ 30$ for supplies. I had a discussion with each participant about the symbol they wanted to make to ensure the idea was feasible (e.g., affordable and 
done within a reasonable amount of time). Some of the participants did not go into detail about their symbol because they wanted it to be a surprise.

After everyone was given sufficient time to finish their projects (approximately 5 weeks), a large sharing circle was held. I had not anticipated having a final sharing circle for participants to share their symbols; this was an event held at the request of the participants. They were eager to share their symbols with everyone. At the request of the research participants, all members of the martial art program were invited, including people who did not participate in the research and children of the parents who participated. The final sharing circle began with a smudge and opening prayer. Once again, the participants are the ones who decided on the format for the circle. Food and drinks were provided. Permission was granted by participants to take pictures of their symbols and videotape the circle specifically to capture the stories that accompanied the symbols. Four of the 11 also provided written stories. The participants gave permission to share their symbols and stories in this publication. Some of the participants presented me with their symbols as a gift at the end of the project.

I will now share a few of the participants' symbols and edited versions of their stories, but before I do, it is important to explain that much of what the participants described related to the social and cultural impacts of participating in the program. As mentioned above in the description of the program, Aboriginal culture and tradition were interwoven in the teaching of the martial arts. The following stories reflect this. For further details on the results of the research, please see Lavallée (2007a, 2007b, 2008).

I know that not all Native people are searching for their identity, but my life has been a life long journey of trying to understand who and what I am. This has caused problems for me. I understand now that the biggest problem was the sense of undeservingness I have. I don't think of it as a lack of self-esteem. Coming here is opening my eyes that I am deserving. I am deserving of my black belt, I am deserving of having people care about me and not hurt me. My Medicine Wheel with the hawk-my clan-symbolizes my healing journey and the growing understanding I have of myself as Anishnaabe. Kwe-As a woman. My undeservingness as a woman-I'm understanding through our informal healing circles in the bathroom and the strength that I get when I walk through these doors that my undeservingness is a symptom that comes from our long history and how we unlearned our ways to respect women. It comes from my Dad and his Dad and so on ... and in turn the men I have selected because I'm comfortable with and expect to be treated unwell. So, my next symbol is The Strong Women's Song. The song that I know has brought me helpers to unlearn this lack of deserving. (Hawk)

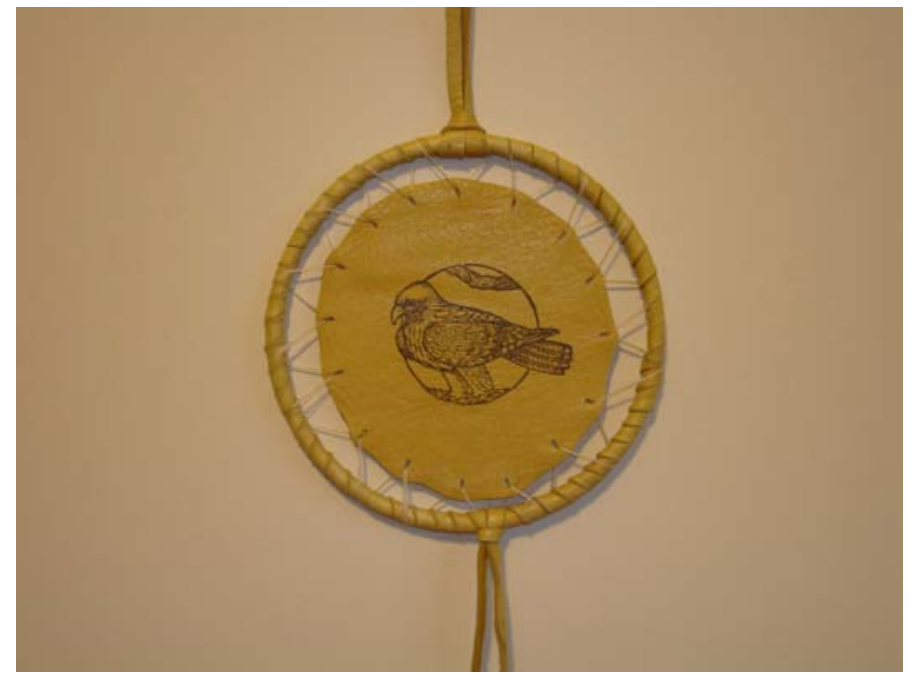

Figure 1. Hawk's medicine wheel 
Hawk's symbols (Figure 1) and story centered on the themes of Native identity and undeservingness. Anderson (2000) spoke about the development of a negative female Aboriginal identity because of societal stereotypes and how these become self-fulfilling prophecies. The undeservingness is part of this self-fulfilling prophecy. The physical activity program at the Native Canadian Centre marked the beginning of Hawk's healing journey.

Unlike Hawk, Nimky-Nene was further along in his spiritual healing journey and his understanding of his identity as an Aboriginal man. He participated in spiritual ceremony, danced, drummed, and sang but felt something was still missing. Once he became physically active again, he felt that his spirit was shinning brighter. Nimky-Nene's symbol (Figure 2) articulated the interconnection of physical activity with spiritual well-being. His symbol was a soap stone carving of a man with a long braid in a tae kwon do uniform. He was holding his spirit energy at his belly.

I was placed with what I call a dying spirit, a fading spirit. I'm a small town boy, I like the bush. Being in the city, I don't have the energy that you get from being in the bush. I needed to get physically active. I didn't have a lot of money. I needed to feel, in my own community - feel just the people and exercise. I didn't have money to join a big club. The only thing I can picture or imagine is how my spirit is in my belly, my energy in my belly. Before I could not feel it unless I was in ceremony, deep in ceremony and now everywhere I walk I can feel it, I can feel it and other people can see it. It's that attraction-kids come to me. I can physically chase them around now. (Nimky-Nene)
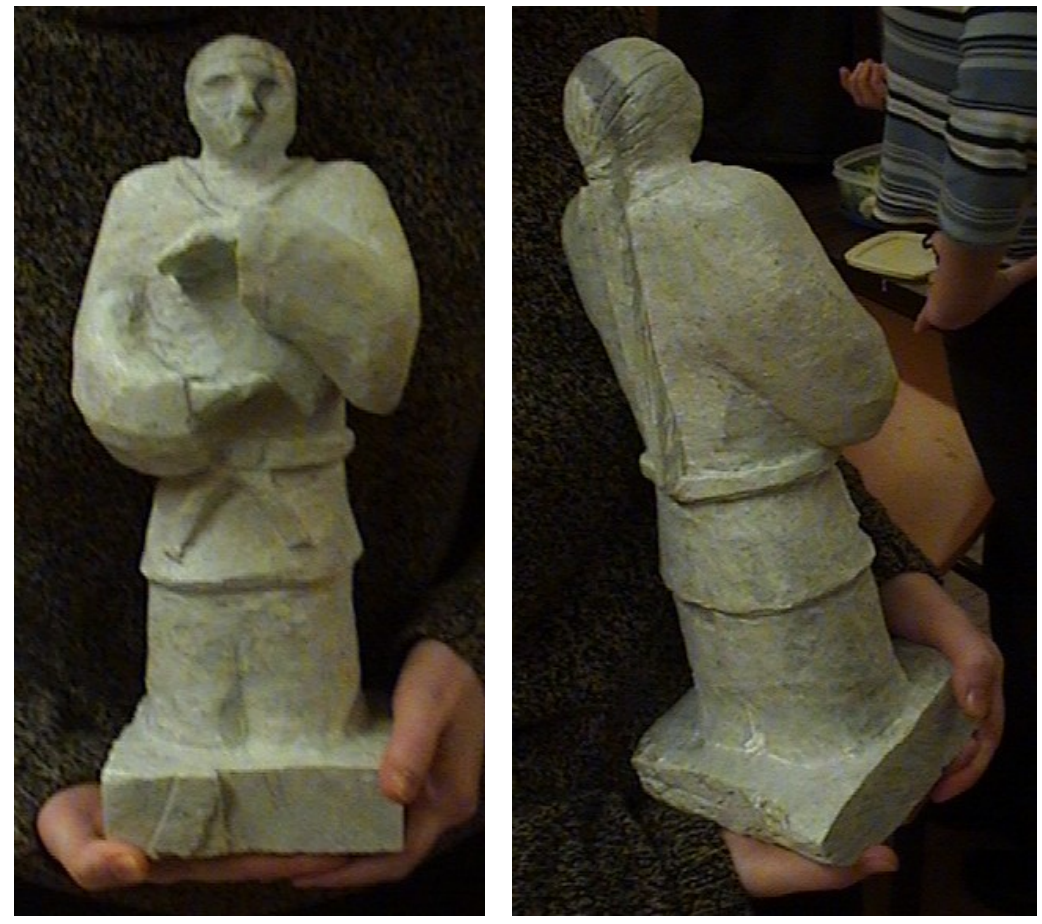

Figure 2. Nimky-Nene's soapstone carving

Turtle's symbol (Figure 3) also expressed the interconnection of her involvement in the pnysicaı actıvity program and how it related to various aspects of her life. She spoke about the holistic growth she experienced as a result of the physical activity program. She called her symbol Threads of Connection, emphasizing the notion of interconnectedness. 


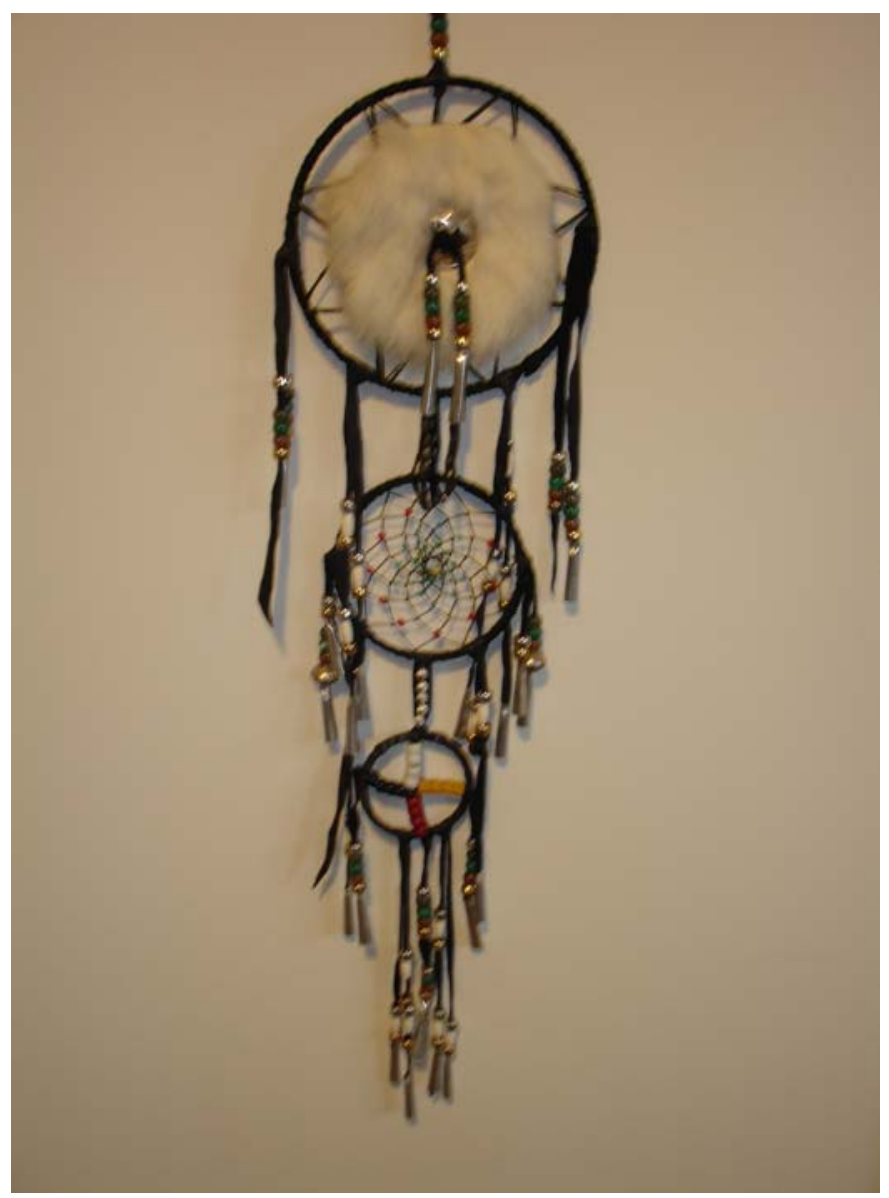

Figure 3. Turtle's medicine shield, dream catcher, and medicine wheel

This piece of artwork was created and designed specifically to provide a symbolic reflection or representation of what Taekwondo means to me. I have discovered that martial art emanates from a deeply spiritual place that ties in with my own personal strong beliefs of aboriginal spirituality. I titled my project "threads of connection" because it seems the most appropriate way to express my experience here and the importance of the program to me. The format was completely natural to me because it is a direct expression of my identity and the interconnectedness of Taekwondo itself in my life. I chose three rings for a multitude of reasons. Some I will explain and some will have to wait for perhaps another time. Circles have no beginning and no end and that's how I have come to view my experience here. It has no real beginning and no end. I will always be a part of this program in some way. The three rings represent the mind, body and spirit principles of martial arts. Each ring is wrapped in black to signify the concept of the great unknown that we all hear [our instructor] refer to. It is also currently where I stand as a black belt in the program. (Turtle)

\section{Challenges in presenting the symbols}

I found the academic requirements of putting this research into the written form of a dissertation and publications limited the details about the symbols. Pictures of the symbols and the stories that accompanied them were included; however, attempting to put the symbols into words is somewhat of a contradiction because words can limit the meaning of the symbols. This challenge was accentuated in trying to explain the songs that two participants selected to describe the meaning of the program. As noted in Hawk's story, one of her symbols was the Strong Women's Song. The second participant to use a song was Crane. His song was Ogitchada, which translates into "a person of great heart.” He stated that this 
song "speaks of our people as warriors, men and women, how strong our people are and how strong our hearts are.” Both songs involve melodies and do not contain words. However, Aboriginal songs have spiritual meaning, and both participants described their personal meaning of the songs. I included their stories about the songs in the written dissertation and other publications. For presentations, I ensured that I had the technology to play the songs in addition to describing the stories because this was a more accurate reflection of their symbol. With the increase of online journals it should be more feasible to include sound bites to allow better representation of songs as symbols.

\section{Analyzing the data}

In an attempt to bridge the two qualitative Indigenous research methods with Western qualitative research methods, the discussions in the sharing circles were audiotaped and transcribed verbatim. I used a common coding method in qualitative research called grounded theory and used the software program N6 (NUD*IST 6 by QSR International) to analyze the data. N6 allows the researcher to select blocks of text and name them based on what is described by the participants. These blocks of text are described as units of meaning and are called nodes. This form of coding that begins with the naming of small blocks of texts is an inductive way of analyzing the data and is thought to be more "grounded" in what participants have said (Berg, 1995).

After coding two of the transcripts, I went through over 200 nodes that came out of the data and began identifying themes. After I had coded all of the transcripts, there were over 700 nodes that were categorized into nine higher order themes. The nine themes were stories of their pasts (where they have come from); stories related to their future (where they are going); the Native Canadian Centre; the martial arts program; physical, mental, emotional and spiritual impacts of the physical activity program; and the way they walk in life. I developed a visual depiction of the higher order themes and presented this to the participants at the large sharing circle. Going back to research participants to confirm themes emerging from the data is referred to as member checking in qualitative research. It is a method of ensuring trustworthiness of the themes (Lincoln \& Guba, 2000). The participants were in agreement with the themes. However, in working with the community research assistant and in presenting the method of analysis to colleagues, it became evident that this "standardized" way of analyzing qualitative data was problematic for this Indigenous approach because it seemed to tear apart the stories of the participants. Because storytelling is an important aspect of Aboriginal culture, I felt this method of analysis was not consistent with the Indigenous research framework that guided this project.

\section{Telling the collective story}

What was needed was to bring the stories back together, which I did by telling a collective story with the nine higher order themes, keeping the individual stories intact by writing about the participants as characters in a play and using the principles of Anishnaabe symbol-based reflection to develop a symbol representing the collective story.

Although there were nine higher order themes, it was challenging to report on the themes individually because they were interconnected. For instance, in the same breath that participants talked about their pasts, they referred to their healing through this program, healing of the emotional and spiritual aspects of themselves, and how this might affect their future. Therefore, for my written dissertation, rather than report on each theme, I wrote short stories that demonstrated the interconnection between the nine themes. For example, in a section called Stories Related to Historic Trauma and Healing, quotes from the participants spoke of their pasts and the impact it had on them today in their healing. Another section, called The Four Directions, told stories about the interrelationship of their involvement in the martial arts program and the impact on their lives. In a section called Relationships, Family and the Urban Aboriginal 
Space, participants reflected on the importance of the Native Canadian Centre as an urban meeting place for Aboriginal people and the impact this had on their sense of community and family (Lavallée, 2007a).

I thought the stories could stand on their own, allowing the reader to interpret them. However, part of a doctoral research project includes the interpretation of the results. Reluctantly, I included a chapter in my dissertation on my interpretations and the significance of the stories in light of other research. I found that my interpretation of the stories reflected on past research but also the history of Indigenous people, particularly the impact of colonization and, more important, decolonization. As noted earlier, the rewriting and rerighting of the Indigenous position in history is an important part of decolonizing research (Smith, 2002), so my initial reluctance changed to appreciation.

Figure 4. Two Métis symbols
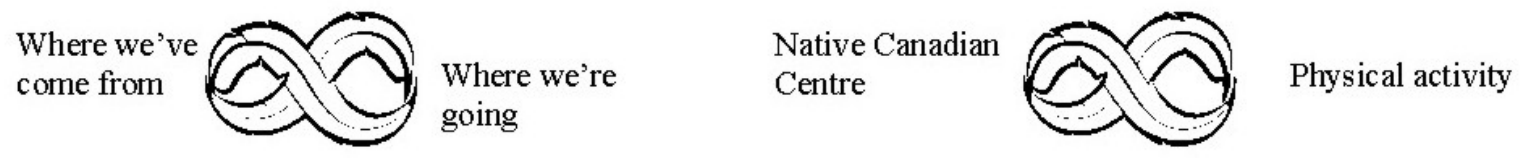

\section{The symbol of the collective story}

Anishnaabe symbol-based reflection was drawn on to make sense of the collective story and interpret the results. Being a visual learner, I began to draw a diagram of how the themes flowed together to tell a collective story. To represent four of the themes, I brought together two Métis symbols (infinity symbol), one representing people's pasts and their futures and the second representing the martial arts program and the Native Canadian Centre (Figure 4).

I superimposed these two Métis symbols together as four petals of a flower, representing these four themes that emerged from the individual stories (Figure 5); specifically, where we have come from, represented in the east, and where we are going, shown in the west. The meeting place of the Native Canadian Centre is represented in the north, and the physical direction of the south houses the physical activity program, martial arts. In the center of these four petals, I placed the four directions, symbolizing what participants described as the physical, emotional, mental, and spiritual impacts of the program. Finally, the stem completes the symbols with the theme "the way we walk in life." The stem is connected to the whole, symbolizing the interrelationship of the participants' experiences. These nine themes are the threads of connection that tell the collective story.

Just as one petal of a flower cannot thrive alone, the nine themes of this collective story were interconnected and cannot be told separately. The flower demonstrates the connectedness of the stories, the threads of connection.

\section{A word about reciprocity}

Within an Indigenous research framework the principle of reciprocity, or giving back, is essential. Reciprocity can occur on multiple levels. The knowledge given to you by the participants is a gift. Recognizing the research participants' knowledge is important. In this research project, participants were given tobacco bundles to demonstrate respect for the knowledge they were sharing and were paid for their involvement. Many expressed the importance of the research allowing them to tell their story; hence, another aspect of reciprocity was giving voice to the participants. 


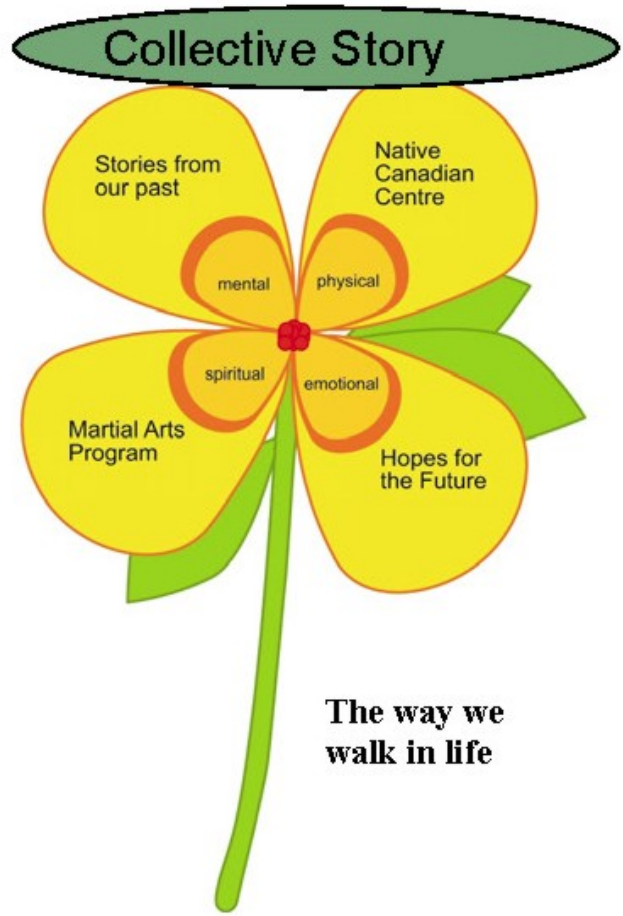

Figure 5. Symbol of the collective story

Reciprocity extends beyond the immediate research participants. In keeping with the decolonizing notion of an Indigenous research framework, reciprocity also includes the advancement of Indigenous ways of knowing. Recently an Indigenous graduate student shared an experience with me where a faculty member discouraged her from using an Indigenous research framework because it is not seen as valid in the academy. We need to give back to future Indigenous scholars by pushing forth the recognition of Indigenous knowledge in the academy and research by publishing this work.

\section{Conclusion}

This research project was a journey of discovery. The most important lesson learned from my experience of working from an Indigenous research framework within the academy was how the "rules" of the academy and of research do not always allow an Indigenous research framework to flourish. Although qualitative research principles were helpful throughout this process, some of these principles were problematic. This was most apparent in the analysis of the stories. I began coding the data the way I had been taught in my qualitative methods courses and past qualitative research experiences. This method fragmented the stories and reduced them to "bits of nature" (Suzuki, 2002). The telling of a collective story with each participant representing a character and the use of a symbol to reflect the meaning of the collective story brought an Indigenous approach back to the research. Nevertheless, the grounded theory method of coding the sharing circles was essential because it helped me organize the themes to tell the collective story.

Indigenous research is decolonizing research (Smith, 2002). As such, it is important that Indigenous ways of knowing resist being categorized under Western concepts, including qualitative inquiry. Indigenous research is not qualitative inquiry; however, the methods used may be qualitative. Indigenous approaches 
or research frameworks encompass far more than just the methods. An Indigenous approach is an epistemology. The methods may be qualitative as in this research, but research undertaking an Indigenous approach could also incorporate quantitative methods. For instance, an Indigenous approach was undertaken in the design of a health survey for Aboriginal peoples, the First Nations Regional Longitudinal Health Survey (Gray, 2005). The medicine wheel concept of health provided the framework and Indigenous research principles incorporated throughout the research process.

The application of an Indigenous research framework in the academy is an important theoretical contribution and provides a different way of knowing, one that endeavors to decolonize the academy. My hope is that this project contributes to the growing scholarly work of bridging Indigenous ways of knowing and Western principles, in this case, qualitative inquiry. I hope that future Indigenous research will not only use methods that are Indigenous and follow appropriate cultural protocols, but that their theoretical or conceptual approach is based on Indigenous knowledge.

\section{Notes}

1. The term Indigenous is used in this paper when referring to Indigenous people in a global context. The term Aboriginal is used when speaking about the Indigenous people of Canada. Aboriginal includes Métis, Inuit, and First Nations regardless of where they live in Canada and regardless of whether they are "registered” under the Indian Act of Canada (Archibald, 2006).

2. In Canada, on-reserve refers to Aboriginal people who reside on the lands that were negotiated with the government through the land treaties.

3. Further information about photovoice can be found at www.photovoice.com.

\section{References}

Absolon, K., \& Willett, C. (2005). Putting ourselves forward: Location in aboriginal research. In L. Brown \& S. Strega (Eds.), Research as resistance. (pp. 97-126). Toronto, Canada: Canadian Scholars' Press.

Anderson, K. (2000). A recognition of being: Reconstructing native womanhood. Toronto, Canada: Sumach.

Archibald, L. (2006). Decolonization and healing: Indigenous experiences in the United States, New Zealand, Australia and Greenland. Ottawa, Canada: Aboriginal Healing Foundation.

Baskin, C. (2005). Circles of inclusion: Aboriginal world views in social work education. Doctoral dissertation, University of Toronto, Canada. Retrieved June 2, 2008, from Dissertations \& Theses: Full Text database. (Publication No. AAT NR27745)

Bastien, B. (2005). Blackfoot ways of knowing: The worldview of the Siksikaitsitapi. Calgary, Canada: University of Calgary Press.

Berg, B. (1995). Qualitative research methods for the social sciences. (2nd ed.). Boston: Allyn \& Bacon. 
Brant-Castellano, M. (2000). Updating aboriginal traditions of knowledge. In G. Dei, B. Hall, \& D. Rosenberg (Eds.) Indigenous knowledges in global contexts (pp. 21-36). Toronto, Canada: University of Toronto Press.

Cajete, G. (2000). Native science: Natural laws of interdependence. Santa Fe, MN: Clear Light.

Canadian Institutes of Health Research. (2007). CIHR guidelines for health research involving Aboriginal Peoples. Retrieved July 25, 2007, from http://www.cihrirsc.gc.ca/e/documents/ethics aboriginal guidelines_e.pdf

Canadian Parks and Recreation Association. (1994). Impact and benefits of physical activity and recreation on Canadian youth-at-risk. Retrieved July 3, 2008, from http://adp.lin.ca/resource//html/impact.htm

Casey, K. (1996). The new narrative research in education. Review of Research in Education, 21, 211253.

Coakley, J. (2002). Using sports to control deviance and violence among youths: Let's be critical and cautious. In M. Gatz, M. A. Messner \& S. J. Ball-Rokeach (Eds.), Paradoxes of youth and sport. (pp. 13-30). Albany, NY: SUNY Press.

Davidson, C. M., Brown, M., \& Moffitt, P. (2006). Student researchers negotiating consent in northern Aboriginal communities. International Journal of Qualitative Methods, 5(2), 1-10. Retrieved March 27, 2009, from https://ejournals.library.ualberta.ca/index.php/IJQM/index

Eigenbrod, R., Kakegamic, G., \& Fiddler, J. (2003). Aboriginal literatures in Canada: A teacher's resource guide. Ottawa, ON: Curriculum Services Canada.

Ellis, J. B., \& Earley, M. A., (2006). Reciprocity and constructions of informed consent: Research with indigenous populations. International Journal of Qualitative Methods. 5(4), 1-9. Retrieved June 2, 2008, from https://ejournals.library.ualberta.ca/index.php/IJQM/index

First Ojibway Network. (2006). Anishinaabemowin: Ojibwe language dictionary. Retrieved July 19, 2006, from http://www.first-ojibwe.net/translations/weshki-ayaad/index.html

Gray, J. (2005). First Nations Regional Longitudinal Health Survey (RHS) 2002/03: The peoples' report. Ottawa, Canada: Assembly of First Nations/First Nations Information Governance Committee. Retrieved March 28, 2009, from http://www.rhs-ers.ca/english/pdf/rhs2002-03reports/rhs2002-03the_peoples_report_afn.pdf

Halas, J. (2001). Playtime at the treatment centre: How physical activity helps troubled youth. Avante, $7(1), 1-13$.

Hartmann, D. (2003). Theorizing sport as social intervention: A view from the grassroots. Quest, 55, 118140.

Kilbourn, B., (2006). The qualitative doctoral dissertation proposal. Teachers College Record, 108(4), 529-576.

Kovach, M. (2005). Emerging from the margins: Indigenous methodologies. In L. Brown \& S. Strega (Eds.) Research as resistance (pp. 19-36). Toronto, Canada: Canadian Scholars’ Press. 
Lavallée, L. (2007a). Threads of connection: Addressing historic trauma of indigenous people through cultural recreational programming. Doctoral dissertation, University of Toronto, Canada. Retrieved June 2, 2008, from Dissertations \& Theses: Full Text database. (Publication No. AAT NR28105)

Lavallée, L. (2007b). Physical activity and healing through the medicine wheel. Pimatisiwin: Journal of Aboriginal and Indigenous Community Health, 5(1), 127-153. Retrieved July 26, 2007, from http://www.pimatisiwin.com/Articles/5.1F_Physical_Activity_and_Healing.pdf

Lavallée, L. (2008). Balancing the medicine wheel through physical activity. Journal of Aboriginal Health, 4(1), 64-71. Retrieved June 1, 2008, from http://www.naho.ca/english/journal/jah04_01/09MedicineWheel_64-71.pdf

Lincoln, Y. S. \& Guba, E. G. (2000). Paradigmatic controversies, contradictions, and emerging confluences. In N. K. Denzin \& Y. S. Lincoln, (Eds.) Handbook of qualitative research. (pp. 163188). Thousand Oaks, CA: Sage.

Loppie, C. (2007). Learning from the grandmothers: Incorporating indigenous principles into qualitative research. Qualitative Health Research, 17(2), 276-284.

McNiff, S. (1998). Art-based research. London: Jessica Kingsley.

Meadows, L. M., Lagendyk, L. E., Thurston, W. E., \& Eisener, A. C. (2003). Balancing culture, ethics, and methods in qualitative health research with aboriginal peoples. International Journal of Qualitative Methods, 2(4), 1-25. Retrieved March 27, 2009, from https://ejournals.library.ualberta.ca/index.php/IJQM/index

Mi’kmaw College Institute. (n.d.). Research principles and protocols: Mi'kmaw ethics watch. Sydney, NS: Cape Breton University. Retrieved July 3, 2008, from http://mrc.uccb.ns.ca/prinpro.html

Minkler, M., \& Wallerstein, N. (2003). Community-based participatory research for health. San Francisco: Jossey-Bass.

Nabigon, H., Hagey, R., Webster, S., \& MacKay, R. (1999). The learning circle as a research method: The trickster and windigo in research. Native Social Work Journal, 2(1), 113-137.

National Health and Medical Research Council. (2003). Values and ethics: Guidelines for ethical conduct in Aboriginal and Torres Strait Islander health research. Melbourne, Australia: Australian Government. Retrieved July 2, 2008 from http://www.nhmrc.gov.au/publications/synopses/e52syn.htm

Native Canadian Centre. (2006). Native Canadian Centre martial arts. Retrieved July 20, 2006, from http://www.ncct.on.ca/martial-arts

Park, P. (1993). What is participatory research?: A theoretical and methodological perspective. In P. Park, M. Brydon-Miller, B. Hall \& T. Jackson (Eds.), Voices of change: Participatory research in the United States and Canada (pp. 1-20). Westport, CT: Bergin \& Garvey.

Piquemal, N. (2001). Free and informed consent in research involving Native American communities. American Indian Culture and Research Journal, 25(1), 65-79.

Restoule, J. P., (2004). Male aboriginal identity formation in urban areas: A focus on process and context. Doctoral dissertation, University of Toronto, Canada. Retrieved June 2, 2008, from 
Dissertations \& Theses: Full Text Database. (Publication No. AAT NQ94516)

Schnarch, B. (2004). Ownership, control, access and possession (OCAP) or self-determination applied to research: A critical analysis of contemporary First Nations research and some options for First Nations communities. Journal of Aboriginal Health, 1(1), 80-95.

Smith, L. T. (1999). Decolonizing methodologies: Research and indigenous peoples. Dunedin, New Zealand: University of Otago Press.

Stevenson, J. (1999). The circle of healing. Native Social Work Journal, 2, 8-21.

Suzuki, D. (2002). The sacred balance: Rediscovering our place in nature (2nd. ed.). Vancouver, Canada: Greystone.

University of South Australia. (2008). Research and innovations series: Indigenous research. Retrieved June 2, 2008, from http://www.unisa.edu.au/res/ethics/indigenous.asp

van Manen, M. (2002). Phenomenology online. Retrieved Feb 3, 2005, from http://www.phenomenologyonline.com

Wang, C., Yuan, Y. L., \& Feng, M. L. (1996). Photovoice as a tool for participatory evaluation: The community's view of process and impact. Journal of Contemporary Health, 4, 47-49.

Wesley-Esquimaux, C., \& Smolewski, M. (2004). Historic trauma and Aboriginal healing. Ottawa, Canada: Aboriginal Healing Foundation. 